\title{
Clinical Usage and Economic Effectiveness of a Recently Developed Epidermal Autograft Harvesting System in 13 Chronic Wound Patients in a University-Based Wound Center
}

\author{
Angela Hulsey ${ }^{1}$, Paul Linneman ${ }^{2}$, Jeff Litt ${ }^{3}$ \\ 1. Medical Student, University of Missouri, Columbia, Missouri 2. Surgery ICU, University of Missouri, \\ Columbia, Missouri 3. Division of Acute Care Surgery, University of Missouri, Columbia, Missouri
}

$\square$ Corresponding author: Jeff Litt, littjs@health.missouri.edu

Disclosures can be found in Additional Information at the end of the article

\section{Received 09/22/2016}

Review began 09/26/2016 Review ended 11/10/2016 Published 11/14/2016

\section{(c) Copyright 2016}

Hulsey et al. This is an open access article distributed under the terms of the Creative Commons Attribution License CC-BY 3.0., which permits unrestricted use, distribution, and reproduction in any medium, provided the original author and source are credited.

\section{Abstract}

Introduction: Chronic wounds are a significant healthcare problem in the United States. Their costs approach 25 billion dollars in the United States. Current wound-care treatments of local wound care, moist dressings, and source control, while necessary for wound healing, are frequently not enough to ensure complete wound closure. The current surgical technique of split-thickness skin grafting is an operative procedure, painful, time-consuming, and leaves significant donor site wounds. A recently developed and marketed epidermal autograft harvester was tested at our university hospital wound center on 13 patients with wounds of various etiologies. Their clinical outcomes were evaluated, as were the costs associated with its usage compared with the potential costs of continued wound care without autograft placement.

Methods: Thirteen patients whose wounds appeared to have "stalled" or reached a plateau in healing by measurement data and visual evidence were chosen to receive an epidermal autograft to accelerate wound closure. Wound-types included diabetic ulcers, venous or lymphedema-related ulcers, surgical site wounds, and traumatic wounds. Time-to-healing in days, when applicable, was captured. Wound center billing and charges were available and evaluated for nine of the 13 patients. Costs of standard care continuation compared with the cost of epidermal autograft technology usage were compared.

Results: Healing rates were $62 \%$; eight of the 13 patients had healed within four months, two were lost to follow-up, and three have wounds that remain open. Four of the patients healed in less than one month. The comparatively rapid closure of the open wound(s) post-epidermal autograft placement potentially reduced healthcare costs based on charges at an average of $\$ 1,153$ per patient and yielded an average of $\$ 650$ to the wound center, not applying the routine costs of dressings applied in the center.

Conclusion: The epidermal autograft harvester accelerated healing in eight of the 13 of the patients (62\%) we treated at the time of the writing of this article. By accelerating wound healing in our patient population, costs associated with subsequent wound care seem to have decreased to a dramatic degree and wound center finances have improved. No wound recurrence has been noted once the wounds had healed in our year-long experience with the technology. In addition, the procedure has been well-tolerated and easy to perform. Given the improved outcomes, cost-savings, and a better financial outlook for the wound center, utilization of the novel epidermal autograft harvester is proving itself to be in the "win-win" 
Categories: Dermatology, Plastic Surgery, General Surgery

Keywords: epidermal autograft, chronic wound, epidermal blister, diabetic ulcer, venous ulcer, wound healing, lymphedema wound

\section{Introduction}

Chronic wounds are sometimes described as a "silent epidemic" in the American health system. Often accompanied by co-morbid conditions, they pose a major threat to public health and are a major financial burden on the United States (US) economy. In 2009, it was estimated that 6.5 million patients developed chronic wounds in the US, with an estimated cost exceeding \$25 billion dollars spent on their treatment and care [1]. Pressure ulcers are regrettably becoming too common in an increasing number of vulnerable patients - the bedridden, immobile, and/or insensate. Patients 65 years or older accounted for $72 \%$ of all of the hospitalized patients reported as having developed a pressure-related wound, with $90 \%$ of those patients insured by government health programs [1]. Expenditures on treating pressure ulcers are estimated to exceed $\$ 11$ billion per year [1]. Similarly, a reasonable estimate is that up to $35 \%$ of all diabetics will develop a diabetic/neuropathic foot ulcer over the course of their lifetime [1]. In 2007, the estimated treatment cost of each foot ulcer was between $\$ 7,439$ and $\$ 20,622$, with an estimated $\$ 9$ billion spent on diabetic foot ulcer care in 2001 [1]. Many of these diabetic patients develop multiple and/or recurrent ulcers over their lifetime and eventual amputations are shockingly common. This cost estimate does not include the hidden or indirect costs associated with loss of productivity, the emotional toll on patients and their families, and the resultant long-term disabilities. The aging and increasingly obese world population, as well as the increasing incidence of diabetes, will continue to worsen the socioeconomic burden of chronic wounds and their complications [1-2].

A chronic wound is one that has been present for 30 or more days. Chronic wounds fail to proceed through the orderly and timely healing process that characterizes acute wound healing, leading to diminished anatomic and functional integrity of the injured site and increasing the likelihood of infection and further wound complications. More rapid healing of these wounds would result in decreased complications, decreased wound care requirements, and earlier return to daily activities, rapidly reducing the burden and cost of care [3].

Split-thickness skin grafting, or autografting, is currently the gold standard for the treatment of major traumatic and burn injury-related skin loss. Skin grafting provides regeneration of both the epidermis as well as underlying dermal elements and decreases wound contraction and extracellular matrix deposition compared with non-grafted full-thickness wounds [2]. However, because split-thickness skin grafting is limited by the availability of donor skin, the resultant donor sites are large, painful, and can themselves become chronic wounds, marked by delayed healing, hypertrophic scarring, and/or prolonged pain [4]. They are associated with immediate and significant pain due to the harvesting process, which exposes sensitive dermal pain receptors. In addition, potential development of pruritus, infection, dyschromia, delayed healing, and subsequent hypertrophic scarring can occur [5-6]. Additionally, since both the epidermis and dermis are captured, the graft retains components of the donor site, such as hair follicles and may not cosmetically match the surrounding skin [6].

Attempts to overcome these limitations have been made. Dr. Cicero Meek, a general practitioner in South Carolina, developed a method of tissue expansion to treat large body surface burns. This technology preceded meshing technology. Meek's technology, developed in 1958, involved mechanical division of the skin graft, providing up to a 10-fold skin expansion, but pieces had to be placed dermal side down for success and, thus, was labor-intensive and 
time-consuming. Alternatively, cultured epithelial autografts (Epicel ${ }^{\circledR}$, Vericel Corp, Cambridge MA) can provide an expansion ratio up to 1:1000, but the grafts are extremely fragile, lack a dermal component, and require extremely expensive techniques and facilities for development [5]. The Xpansion ${ }^{\circledR}$ Micro-autografting System (SteadMed Medical, Fort Worth, TX) uses splitthickness skin micrografts, which increase the expansion ratio to 1:100, is less labor intensive, and thus, can be performed in an outpatient setting with local anesthetic [5]. However, the system can only be used on small wounds, and donor site healing, while smaller than splitthickness skin grafting, is still associated with pain and scarring.

Epidermal blister grafting has traditionally been time-consuming, labor-intensive, and painful. Former harvesting techniques included using large-volume syringes to raise primarily epidermis-composed blisters, taking multiple procedures to complete, thereby, leading to an uncomfortable and time-consuming process. Additionally, inadequate handling of the graft could lead to tearing and improper orientation, resulting in graft failure [6]. The CelluTome ${ }^{\mathrm{TM}}$ Epidermal Harvesting System (Acelity Inc, San Antonio, TX was developed to help overcome these obstacles [4]. Per its accompanying literature, this device "is a harvesting tool that creates suction-epidermal blisters using a constant negative pressure of 400 to $500 \mathrm{mmHg}$ at $37^{\circ}$ to $41^{\circ}$ C. The suction blisters are developed inside the disposable harvester, which consists of two stainless steel plates with an array of $1.75-\mathrm{mm}$ holes and a cutter blade. More than 128 blisters can be created over an area of $25 \mathrm{~cm} 2$ of donor skin, which is then peeled away with a (transparent) dressing and applied over the recipient site” [5]. This technology offers a minimally invasive, relatively pain-free harvesting technique that creates minimal donor site damage and scarring, increased expansion ratios, and can be performed easily and relatively pain-free in the outpatient setting. The CelluTome ${ }^{\mathrm{TM}}$ technology makes epidermal grafting quality more consistent and the procedure economically and practically more feasible. As a result, the epidermal graft may have a role in reducing healing time in chronic and small acute wounds. Potentially, there could be a significant impact on the overall cost of chronic wound care. This case review series evaluates the outcomes of 13 recently treated patients with chronic wounds who underwent grafting of epidermal skin grafts using the CelluTome ${ }^{\mathrm{TM}}$ system.

\section{Materials And Methods}

\section{Patient selection}

Patients were selected based on the failure of their wounds to heal despite utilization of standard wound care treatments in the outpatient setting in our university-based community wound center. Standards of care at our wound center include optimization of moist woundhealing, drainage control measures, and usage of off-loading and compression in appropriate wounds. Patient characteristics are delineated in Table 1 . We evaluated our patient selection criteria (type, size, and location of their wounds), comorbidities, patient age and sex, and, when applicable, time-to-wound-closure. In addition, by reviewing our billing documentation, we were able to estimate costs associated with wound care regimens prior to placement of the epidermal autograft. 


\title{
Cureus
}

\author{
Patient Age Sex Pertinent Comorbidities \\ 129 M Smoker, Type I diabetes mellitus \\ $236 \quad \mathrm{~F} \quad$ Wheelchair bound, venous stasis, lymphedema, \\ $352 \quad$ M Smoker, hepatitis C \\ $4 \quad 36 \quad M \quad$ Hypertension, asthma \\ $5 \quad 72 \quad$ M Hypothyroidism, Type II diabetes mellitus, COPD, chronic kidney disease \\ $6 \quad 60 \quad$ M Type II diabetes mellitus, asthma \\ $\begin{array}{llll}7 & 37 & \text { M } & \text { Smoker, paraplegia/wheelchair bound }\end{array}$ \\ $8 \quad 79 \quad \mathrm{~F} \quad$ Venous stasis, hypertension, anemia \\ $953 \quad$ F $\quad$ Smoker, history of DVT/ peroneal thrombosis \\ $10 \quad 61 \quad$ M $\quad$ Coronary artery disease, Parkinson disease, obstructive sleep apnea \\ $11 \quad 68 \quad M \quad$ Hypertension, prostate cancer \\ $1262 \mathrm{M} \quad$ Paraplegia/wheelchair bound, morbid obesity, Type II diabetes mellitus, peripheral neuropathy, \\ lymphedema \\ Rectal cancer s/p neoadjuvant therapy and resection, ventral hernia $s / p$ mesh placement, \\ ileostomy, abdominal mucous fistula, COPD, hyperlipidemia
}

\section{TABLE 1: Patient Characteristics}

COPD: chronic obstructive pulmonary disease; DVT: deep vein thrombosis

\section{Procedure: epidermal autograft harvesting and placement}

The CelluTome ${ }^{\mathrm{TM}}$ Epidermal Harvesting System device was used to create epidermal micrografts for autograft placement to chronic wounds that had "stalled" in their healing trajectory, determined primarily by minimal change in size and/or appearance for two to four consecutive visits to the wound center. Verbal consent for the procedure was obtained prior to the procedure in all patients. Each donor site was prepped with $70 \%$ isopropyl alcohol after hair was clipped. The epidermal autograft harvester was adequately placed on the medial thigh in all but one patient, whose thigh was too large for the accompanied strap system, in whom the medial calf was used instead. Suction with a machine-setting negative pressure of 400 to 500 $\mathrm{mmHg}$ and warmth of $37^{\circ}$ to $41^{\circ} \mathrm{C}$ were applied for an average of 44 minutes (range: $33-55$ minutes), with a visually confirmed observation of sufficient development of epidermal blisters. A silicone-based, non-adherent dressing was placed over the blisters, confirming adherence. The CelluTome ${ }^{\mathrm{TM}}$ device was then activated, excising the blisters. Sufficient blisters were then noted on the dressing and were transferred by hand in the proper polarity to the patient's surgically prepared (i.e. surgically debrided) recipient wound bed. All donor sites were dressed with a transparent adhesive dressing. All wound sites were dressed based on characteristics unique to each wound and the standard of care for that specific wound type. Follow-up was scheduled for approximately one week after application (six or seven days postprocedure). 


\section{Cureus}

\section{Wound care and measurement}

The wound care regimen was patient and wound etiology-based. Standard wound care paradigms were used, i.e. maintenance of a moist wound environment, maintaining offloading when applicable, medical-grade compression utilization for venous leg ulcers, surgical debridement, and assessment and treatment for infection, if appropriate.

Wounds were measured in a standard fashion. The length was measured at its longest point, width at its widest, and depth at its deepest point.

\section{Results}

Thirteen wounds were treated. Five were leg ulcers with venous stasis or lymphedema, two were traumatic wounds, and three were diabetes-related wounds. Three wounds were at surgical sites, including one burn graft failure area, one neurosurgical dehiscence, and one abdominal wound with granulated mesh. Seven of the wounds were healed by three months after the epidermal graft placement, and another healed by four months after placement of the epidermal graft. Two were lost to follow-up, and three have not healed as of this time. One patient had two epidermal graft applications with healing approximately three months after the first application (Table 2). Specific patient information is delineated in Table 3.

\section{Outcome}

Healed at one month

Healed at two months

Healed at three months

Healed at four months

Not healed

Lost to follow-up

\section{Number of Patients}

4

1

1

1

3

2

\section{TABLE 2: Outcome Summary}

Patient, Etiology, and Location of

Wound

\#1, Non-healing traumatic wound
present for years due to DM; scalp

\section{Pre-}

CelluTome

Appearance

and Size

$3.1 \times 2.6$

$\mathrm{cm}$
Wound Healing

Progression; Days Post- Final Outcome

graft; Size

Patient was lost to follow-up.

Reevaluated approx 8 months later, local wound care ensued, and patient again lost to follow-up. Stated wound had healed and reopened. 


\section{Cureus}

2, Ulcer secondary to venous stasis and lymphedema, present for years on the medial malleolus at the ankle (Calf donor).

3, Chronic dehisced surgical wound present for months following instrumentation s/p trauma, which was complicated by cervical osteomyelitis, failed STSG, and unsatisfactory negativepressure wound therapy.

\section{4, Chronic wound of unknown origin} present for months, treated at outside wound center initially, left lower extremity. Failed to progress with standard compressive therapy.

5, Diabetic foot ulcer, present for months complicated by osteomyelitis requiring fifth ray amputation which was treated with a wound vac for two months postoperatively; right fifth toe amputation site

\section{6, Chronic diabetic foot ulcer} complicated by osteomyelitis requiring amputation of first toe. Healing of amputation site was complicated by failed STSG and wound vac therapy; left first toe amputation site

\section{7, Chronic lower extremity wound} present for 15 months secondary to vascular disease; right calf

8 , Chronic venous stasis wound present for 23 months with failed Silver-based and Unna boot therapy; right medial malleolus

9, Chronic wound secondary to hematoma which was surgically debrided and treated with a wound vac; right thigh

$\begin{array}{ll}3.0 \times 2.6 & 6 \text { days post } \\ \mathrm{cm} & \text { graft; } 3.0 \mathrm{x} \\ & 2.75 \mathrm{~cm}\end{array}$

\section{6 days post}

$3.5 \times 2 \mathrm{~cm}$ graft; 3 × 3.5

days post graft; $5.5 \times 3$ $\mathrm{cm}$ (note

$6 \times 5 \mathrm{~cm}$ epidermal blister grafts present on wound bed)

\section{6 days post}

$5.5 \times 1 \mathrm{~cm}$ graft; 1 x 5 $\mathrm{mm}$

$6.5 \times 4.5$ $\mathrm{cm}$

$6 \times 3.5 \times$ $0.5 \mathrm{~cm}$

$3 \times 1.5 \times$ $0.3 \mathrm{~cm}$

$3 \times 2.1 \mathrm{~cm}$

6 days post graft; 6 × 3.5 $\mathrm{cm}$

6 days post
graft; $3 \times 1.7$
$\mathrm{~cm}$
6 days post post

graft; 1.8 $x 1.8 \mathrm{~cm}$ with $0.8 x$

Wound closed at 85 days

$0.8 \mathrm{~cm}$

open

base

41 days
post
graft; $4 \mathrm{x}$
$3 \mathrm{~mm}$
opening
with no
depth

29 days

post

graft; 1 x

$0.5 \mathrm{~cm}$

13 days

post

graft; no

open

wound

27 days

post 148 days post graft; $5 \times 1.5 \mathrm{x}$ graft; 6 x $0.25 \mathrm{~cm}$

$2 \mathrm{~cm}$

13 days

7 days post post graft; 6 x 3.5 graft; 6 x $x 0.5 \mathrm{~cm} \quad 3.5 \times 1$

Patient care transferred to other surgical service

$\mathrm{cm}$

22 days post graft; 2.9 $\times 1.9 \mathrm{~cm}$ graft; 3 x 2.1 cm

13 days post graft; 2 x $1 \mathrm{~cm}$
55 days post graft; epithelium remains intact
Wound closed at 57 days

Wound closed at 45 days

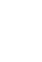

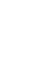




\section{Cureus}

10, Chronic wound present for months secondary to third degree burn with failed STSG; left lateral malleolus

11, Chronic lower extremity wound present for 3 years secondary to lymphedema and footwear trauma with previously failed Unna boot therapy; left foot near medial malleolus

12, Chronic lower extremity wound present for $>1$ year secondary to diabetes; left medial foot

13, Large abdominal wound secondary to surgical complications; abdomen

$\begin{array}{lll}5 \times 1 \mathrm{~cm} & 11 \text { days } & \text { post } \\ & \text { post graft } 3 \times & \text { graft; no } \\ 1 \mathrm{~cm} & \text { open } \\ & & \text { wound }\end{array}$

Repeat grafting was performed 34 days after the original graft due to

$4 \times 2.6 \mathrm{~cm} \quad$ graft $4.5 \times 2.5$ cm

slowed/stalled healing. post graft $3.5 \times 2.5$ $\mathrm{cm}$

Shown above is 21 days post second graft, measuring $1.9 \mathrm{x}$ $1.7 \mathrm{~cm}$

27 days $\square$ 34 days post graft; $3 \times 1.5$

6 days post

$2 \times 2.3 \mathrm{~cm} \quad$ graft; $2 \times 2$ $\mathrm{cm}$

post cm Note: wound healed to 1.7 graft; $3 \times \quad \times 1.7 \mathrm{~cm} 20$ days post graft, $2 \mathrm{~cm}$ yet healing slowed thereafter

$14 \times 5 \mathrm{~cm}$

$\begin{array}{ll}6 \text { days post } & \text { post } \\ \text { graft; } 14 \times 2 & \text { graft; } \\ \mathrm{cm} & 13.2 \times 5 \\ & \mathrm{~cm}\end{array}$

20 days

$\mathrm{cm}$

TABLE 3: Wound Characteristics and Progression 


\section{Cureus}

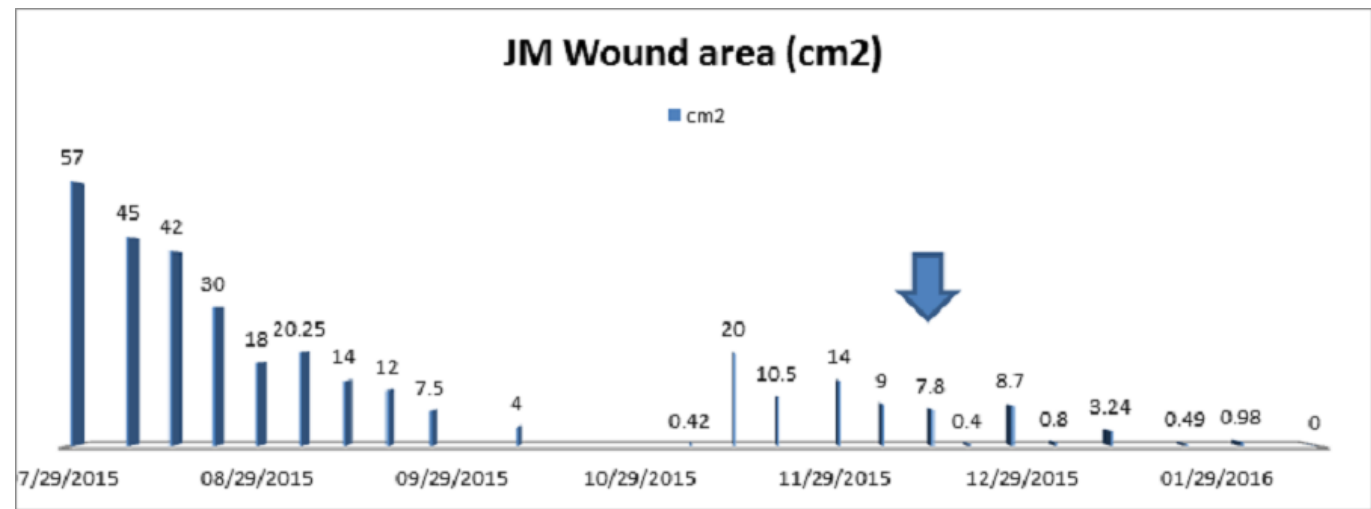

FIGURE 1: Representative Trend Line of Wound Healing in

\section{Patient 2}

Lg arrow indicates placement of epidermal graft.

$\begin{array}{ll}\text { Pt \# } & \text { Saved clinic charges } \\ 1 & \text { NA, lost to follow-up } \\ 3 & \$ 2,148 \text { (6 wk Unna boot) } \\ 4 & \$ 852 \text { (4 clinic visits) } \\ 5 & \$ 1,252 \text { (4 week Unna boots) } \\ 6 & \$ 2,100 \text { (4 weeks TCC) } \\ 7 & \text { NA, still open wound } \\ 8 & \text { NA, lost to follow-up } \\ 9 & \$ 1,252 \text { (4 weeks Unna boots) } \\ 10 & \$ 768 \text { (4 weeks vac dressing) } \\ 11 & \text { \$852 (4 weeks clinic visits) } \\ 13 & \text { NA, still following } \\ \end{array}$

\section{TABLE 4: Potential Savings Due to Reduced Healing Time}

NA: not applicable; TCC: total contact cast 
Specifically, estimated costs associated with wound center-based care based on billing information are as follows:

- Clinic f/u fee, level 3 visit: \$122/visit

- Clinic facility fee: $\$ 91$

- Professional fee for Unna boot: \$100/application

- Professional fee vac change: $\$ 70 /$ procedure

- Unna boot facility fee: \$136/application

- Average total contact cast (TCC) application professional fee: \$434/application

- Average charge of placement of epidermal autograft in wound center setting: \$1,827

- Average reimbursement for placement of epidermal autograft: $\$ 530$

The CelluTome ${ }^{\mathrm{TM}}$ Epidermal Harvesting System (Acelity Inc, San Antonio, TX) device has costs associated with its usage as well. The cost of one harvester is approximately $\$ 350$ for our wound center. The harvesters are non-reusable; any repeat applications (performed on one patient at the time of this submission) incur a new harvester being used with a resultant duplication of the costs. Procedural charges are significant but, in all but two cases, have yielded significant payments to the wound center, averaging approximately $\$ 650$ for the nine patients on whom billing data and insurance payment data is currently available, including two pending payments. Regardless of payment information, however, the prospect of earlier wound closure, earlier cessation of wound care and its resultant costs, and, most importantly, even in today's financially-sensitive environment, earlier return of the patient to their normal life without the physical, financial, and emotional burden, of a chronic wound cannot be overestimated. Even if this procedure was entirely cost-neutral, which it has not been, the benefit of healing a recalcitrant wound in a wound healing center cannot be overestimated. Patient satisfaction improves remarkably in healed patients as does physician satisfaction, nursing satisfaction, and family satisfaction.

\section{Conclusions}

The CelluTome ${ }^{\mathrm{TM}}$ Epidermal Harvesting System (Acelity Inc, San Antonio, TX) device markedly accelerated healing in eight of the 13 patients we treated at the time of the writing of this article. Unfortunately, two patients were lost to follow-up. Nonetheless, by accelerating wound healing in our patient population, all costs associated with subsequent wound care seem to have decreased to a dramatic degree and wound center finances have improved. Even more dramatically, the healing our patients experienced was gratifying and honestly surprising in certain patients (specifically, Patients 2 and 8, whose wounds were treated for years prior to seeking care with our wound specialists). Even in accounting for the expense of the harvester and the professional fees associated with the procedure, significant cost savings were noted with the usage of the CelluTome ${ }^{\mathrm{TM}}$ system in those patients who healed, i.e. 8/13 (62\%) of the patients whom we treated. The procedure was well tolerated by all of the patients, and thus far, in our patients who healed, no wound recurrence has been observed since starting to use this technology and grafting technique over the past year. Given these improved outcomes, costsavings, and a better financial outlook for the wound center, utilization of the CelluTome ${ }^{\mathrm{TM}}$ Epidermal Harvesting System is proving itself to be in the "win-win" category of wound care treatments with little-to-no downside, markedly improved healing rates, and subsequent 
improvement in patient, caregiver, and staff satisfaction.

\section{Additional Information}

\section{Disclosures}

Human subjects: Consent was obtained by all participants in this study. Animal subjects: All authors have confirmed that this study did not involve animal subjects or tissue. Conflicts of interest: In compliance with the ICMJE uniform disclosure form, all authors declare the following: Payment/services info: All authors have declared that no financial support was received from any organization for the submitted work. Financial relationships: All authors have declared that they have no financial relationships at present or within the previous three years with any organizations that might have an interest in the submitted work. Other relationships: All authors have declared that there are no other relationships or activities that could appear to have influenced the submitted work.

\section{References}

1. Sen CK, Gordillo GM, Roy S, Kirsner R, Lambert L, Hunt TK, Gottrup F, Gurtner GC, Longaker MT: Human skin wounds: a major and snowballing threat to public health and the economy . Wound Repair Regen. 2009, 17:763-71. 10.1111/j.1524-475X.2009.00543.x

2. Oliverio J, Gero E, Whitacre KL, Rankin J: Care algorithm: Diagnosis and treatment. Adv Skin Wound Care. 2016, 29:65-72. 10.1097/01.ASW.0000473132.88076.af

3. Lazarus GS, Cooper DM, Knighton DR, Margolis DJ, Pecoraro RE, Rodeheaver G, Robson MC: Definitions and guidelines for assessment of wounds and evaluation of healing . Arch Dermatol. 1994, 130:489-93. 10.1001/archderm.1994.01690040093015

4. Serena TE: Use of epidermal grafts in wounds: a review of an automated epidermal harvesting system. J Wound Care. 2015, 24:30-34. 10.12968/jowc.2015.24.Sup4b.30

5. Singh M, Nuutila K, Kruse C, Robson MC, Caterson E, Eriksson E: Challenging the conventional therapy: Emerging skin graft techniques for wound healing. Plast Reconstr Surg. 2015, 136:524e-30e. 10.1097/PRS.0000000000001634

6. Osborne SN, Schmidt MA, Harper JR: An automated and minimally invasive tool for generating autologous viable epidermal micrografts. Adv Skin Wound Care. 2016, 29:57-64. 10.1097/01.ASW.0000476072.88818.aa 